\title{
Genetic Factors in Parkinson's Disease and Potential Therapeutic Targets
}

\author{
Jian Feng*
}

Department of Physiology and Biophysics, State University of New York at Buffalo, Buffalo, NY 14214, USA.

\begin{abstract}
Parkinson's disease is a neurodegenerative movement disorder caused by a combination of environmental and genetic factors. Recent human genetic studies have identified five genes that are linked to Parkinson's disease (PD): $\alpha$-synuclein, parkin, UCH-L1, DJ-1 and NR4A2. Among these genes, a variety of mutations in the human parkin locus have been found in many PD cases, both familial and sporadic. Parkin appears to be the most prevalent genetic factor in PD. It encodes for a protein-ubiquitin E3 ligase, whose loss-offunction mutations cause specific degeneration of dopamine (DA) neurons in substantia nigra in human patients. The accumulation of parkin substrates is thought to be the key factor in the selective death of DA neurons. Rapid progress in the identification of these substrates and the generation of genetic animal models has produced a plethora of knowledge about the biological function of parkin and its role in PD. These studies also offer novel pharmacological targets for the development of more selective therapeutic strategies. In this review, I will summarize results from this fast expanding field and discuss their potential implication in the treatment of Parkinson's disease.
\end{abstract}

Key Words: parkin, $\alpha$-synuclein, Parkinson's disease, ubiquitination, misfolding, microtubule, dopamine, tubulin.

\section{INTRODUCTION}

Parkinson's disease is one of the most frequent neurodegenerative disorders, affecting 1 2\% of people over 65 years of age [27]. Symptoms of this disease include resting tremor, muscle rigidity, bradykinesia, gait disturbance and postural instability [88]. Although the etiology of PD is far from clear, and the complicated spectrum of its symptoms suggests that PD is caused by a variety of factors, the most prevalent pathological feature in PD patients is the progressive death of dopaminergic neurons in substantia nigra pars compacta (SNpc). Such a loss results in the reduction of dopaminergic inputs in striatum, a region critically involved in the control of movements and motor planning [79]. In most forms of PD, loss of nigral dopaminergic neurons is often accompanied by Lewy bodies. These intracytoplasmic inclusions are also found in other brain regions, such as locus cerulus, nucleus basalis, hypothalamus and cerebral cortex. Although neurodegeneration also occurs in these tissues, the loss of dopaminergic neurons in $\mathrm{SNpc}$ is far more pervasive and appears to contribute most significantly to the symptoms of PD [93]. Consistent with this, one of the most effective treatments of $\mathrm{PD}$ is dopamine replacement therapy. Another line of evidence supporting the critical role of nigral dopaminergic neurons in the pathology of PD comes from studies on MPTP (1,2,3,6-methyl-phenyl-tetrahydropyridine) [66], 6OHDA (6-hydroxydopamine) [52] and rotenone [8]. These toxins selectively destroy dopaminergic neurons in SN. Drug addicts who took MPTP exhibited symptoms that bear striking resemblance to those found in PD patients. Animal models using MPTP [96], 6-OHDA [52], or rotenone [8]

\footnotetext{
*Address correspondence to this author at Department of Physiology and Biophysics, State University of New York at Buffalo, 124 Sherman Hall, Buffalo, NY 14214, USA; Tel: 716-829-2345; Fax: 716-829-2699; E-mail: jianfeng@buffalo.edu
}

further connect the death of nigral dopaminergic neurons to symptoms of PD.

Although it is now generally believed that the death of nigral dopaminergic neurons causes PD, we still do not understand molecular and cellular mechanisms underlying the specific loss of these neurons. Administration of levodopa/carbidopa is beneficial for many patients, especially in the beginning stage of therapy. However, as the disease progresses, more extensive loss of nigral dopaminergic neurons necessitates increased dose of levodopa, which leads to many side effects, such as levodopa-induced dyskinesia, personality changes, dementia, withdrawal, depression, etc. The side effects of levodopa therapy very often become so debilitating to the patients that doctors are forced to limit dosage of the drug when patients need it most. In the advanced stage of PD, levodopa therapy is usually ineffective, as the chronic loss of dopamine innervation in the striatum has perturbed the normal functions of many brain regions [30]. The resurgence of surgical methods and the recent development of deep brain stimulation for advanced stage patients hold great promises while raising many unanswered questions. It is clear that a better understanding of how nigral dopaminergic neurons die will greatly facilitate the discovery of novel therapeutic strategies for PD.

\section{GENETIC FACTORS IN PARKINSON'S DISEASE.}

Long-term epidemiological studies indicate that many factors contribute to the incidence of PD [115]. These include exposure to certain toxins, living in a rural environment, etc. Despite extensive searches for specific toxins in brains of PD patients, no conclusive findings in human population have been obtained so far on the contribution of environmental factors to PD. On the other hand, it has been noted for a long time that approximately 
$5 \sim 10 \%$ of PD cases are familial [88]. Recent progress in molecular genetics studies of families with PD has led to the identification of several loci that are linked to certain inherited forms of PD. These include $\alpha$-synuclein (PARK1) on chromosome 4q21-23 [94, 95], parkin (PARK2) on chromosome 6p25.2-27 [57], UCH-L1 (PARK5) on chromosome 4p14 [70], DJ-1 (PARK7) on chromosome 1 p36 [10], and NR4A2 on chromosome 2q22-23 [67]. In addition to these genes, several other loci have been implicated in PD, although the responsible genes have not been identified.

\section{II.A. $\alpha-$ Synuclein}

The first evidence that some forms of PD could have a purely genetic basis was reported by Golbe and co-workers in the initial account of the Contursi kindred [40]. Through linkage analysis, Polymeropoulos et al. mapped a gene for PD to a locus at chromosome 4q21-23 (PARK1 locus) [94]. They later identified a point mutation (A53T) in the $\alpha$ synuclein gene, which was located in this locus and was linked to an early onset, autosomal dominant form of familial PD [95]. Another missense mutation (A30P) in $\alpha$ synuclein was identified in an independent study [62]. However, subsequent investigations involving a large number of patients with sporadic or familial PD have failed to identify any mutations in the $\alpha$-synuclein gene $[15,105$, $118,119]$, indicating that this gene is involved in very small population of PD patients.

Despite the rareness of mutations in $\alpha$-synuclein, in vitro studies demonstrate that compared to the wild-type protein, both $\alpha$-synuclein mutants show accelerated formation of Lewy body-like fibrils and spherical assemblies when they are present at high concentration in solution [21, 84]. Overexpression of human wild-type $\alpha$-synuclein with a PDGF $\beta$ promoter in neuronal tissues in mice results in progressive accumulation of $\alpha$-synuclein- and ubiquitinpositive inclusions resembling Lewy bodies. The transgenic mice also exhibit loss of dopaminergic neurons in $\mathrm{SN}$ and significant deficits in motor performance in the rotorod test [76]. Similar results are obtained when wild-type, A53T, or A30P mutants were overexpressed in Drosophila [33]. Furthermore, $\alpha$-synuclein knockout mice display altered dopamine release, reduced striatal dopamine content and attenuated locomotor response to amphetamine [2]. These lines of evidence suggest that $\alpha$-synuclein is critically involved in the formation of Lewy bodies and the death of nigral dopaminergic neurons under pathological conditions, such as overexpression or mutations. However, other lines of transgenic mice expressing either wild-type or mutant $\alpha$ synuclein under the prion promoter or tyrosine hydroxylase (TH) promoter do not show significant degeneration of dopaminergic neurons in substantia nigra, although many other types of neurons are significantly degenerated, especially by the A53T mutant [38, 68, 97]. Further studies are necessary to resolve the discrepancies in various $\alpha$ synuclein transgenic mice.

Interestingly, injection of MPTP in mice or primates leads to increased expression [120] and aggregation [61] of $\alpha$-synuclein. On the other hand, systemic administration of rotenone in rats produces ubiquitin- and $\alpha$-synuclein-positive intracellular inclusions that are reminiscent of Lewy bodies [8]. Both MPTP and rotenone cause selective degeneration of dopaminergic neurons in SNpc and PD-like symptoms in these animal models, which suggests that environmental neurotoxins may interact with genetic factors, such as $\alpha$ synuclein, in the pathogenesis of PD.

\section{II.B. Parkin}

Linkage studies in a few Japanese families with Autosomal Recessive Juvenile Parkinsonism (AR-JP) led to the identification of a locus on chromosome 6q25.2-q27 (PARK2 locus) [77]. Using positional cloning and exon trapping techniques, Kitada et al. cloned a large gene $(1.3 \mathrm{Mb})$ in this region whose internal deletion was correlated with PD symptoms. It was named parkin to reflect its connection with the disease [57]. A number of follow-up studies have shown that point mutations, internal deletion and truncations occur in many AR-JP patients with diverse ethnic backgrounds [1, $42,43,69,73]$. In contrast to patients with sporadic PD, the majority of AR-JP patients do not have Lewy bodies, suggesting that parkin may be required for the efficient formation of these cytoplasmic inclusions [25].

In addition to the causative role of parkin in AR-JP, its mutations are a significant factor in idiopathic forms of Parkinson's disease. A recent study has found very high degree of linkage (with a logarithm of odds score of 5.47) between parkin mutations and sporadic cases in families with at least one case of early-onset PD ( $<40$ years) [104]. In a total of 307 families with idiopathic PD, parkin mutations have been found in $5 \%$ of them (18\% in the early-onset cases and $2 \%$ in the late-onset cases) [89]. These results indicate that parkin is the most important genetic factor in PD. I will discuss its biological functions in detail later.

\section{II.C. UCH-L1}

A missense mutation (I93M) in the ubiquitin carboxylterminal hydrolase L1 (UCH-L1) gene was identified in a German family with autosomal dominant PD [70]. UCH-L1 is a brain-specific deubiquitinating enzyme that is present in Lewy bodies. The I93M point mutation causes a $50 \%$ reduction in catalytic activity of the enzyme, which is postulated to affect protein degradation in the brain. However, the mutation identified in the small German family has incomplete penetrance [70]. Additional studies on several PD kindreds fail to identify any mutation in this gene [35]. Furthermore, null mutation of UCH-L1 gene in the gracile axonal dystrophy $(\mathrm{gad})$ mouse exhibits phenotypes that are markedly different from those of PD [100]. It is still unclear to which extent UCH-L1 is involved in the etiology of PD, although a recent study suggests that UCH-L1 may have two opposing enzymatic activities: an ubiquitin $\mathrm{C}$ terminal hydrolase and a dimerization-dependent ubiquityl ligase, which may be important in PD pathogenesis [71].

\section{II.D. DJ-1}

Very recently, two mutations in the DJ-1 gene were found in two families that have an autosomal recessive form of early-onset Parkinsonism (PARK7) [10]. One of the mutations is a point mutation (L166P); the other is a $14 \mathrm{~kb}$ deletion that removes the first five exons. In both cases, only 
homozygous family members are affected, while heterozygous carriers are apparently free of any PD symptoms [10]. It suggests that the mutations cause loss of function of the gene product, which may be critically involved in PD. The known functions of DJ-1 appear to be quite diverse and do not provide any obvious connection to Parkinson's disease. It has sequence homology to some prokaryotic proteins such as ThiJ, which is involved in thiamine synthesis; PfpI, a protease; araC, a transcription factor; and certain glutamine amidotransferases [10]. Human DJ-1 is first identified as an oncogene that interacts with c-myc or h-ras to increase cell transformation [82]. Another group has found that it is a regulatory subunit of an RNA-binding protein [46]. In addition, the rodent DJ-1 gene (also known as Contraception-Associated Protein 1, CAP1) appears to be a sperm protein that participates in fertilization [87, 121]. Most interestingly, DJ-1 binds to PIAS, a SUMO-protein E3 ligase [113] that regulates activities of certain transcription factors [60]. Consistent with this, DJ-1 is sumoylated at lysine 130 [113]. There is also evidence that DJ-1 is modified in response to $\mathrm{H}_{2} \mathrm{O}_{2}$ or the pesticide Paraquat (an agent linked to higher incidence of PD) [80, 81]. Oxidative stress also induces the transcription of the yeast DJ-1 homologue [26]. Furthermore, in transfected COS7 and PC12 cells, the L166P mutant of DJ-1 is co-localized with mitochondria, in contrast to the diffuse cytoplasmic and nuclear localization of the wild-type protein [10]. As mutations in the DJ-1 gene appears to be very rare [22], further studies are necessary to establish the involvement of this versatile protein in Parkinson's disease.

\section{II.E. NR4A2/Nurr1}

The most recently identified PD gene is NR4A2, also commonly known as Nurr1 [67]. Two mutations (a single nucleotide deletion and a point mutation) have been found in the first exon of NR4A2 in one allele of 10 patients with an autosomal dominant form of PD. The clinical symptoms of these patients are not significantly different from the typical PD features.

NR4A2/Nurr1 is a transcription factor in the nuclear receptor superfamily. It plays a critical role in the development of midbrain dopaminergic neurons. Nurr1 knockout mice do not have dopamine neurons in the midbrain and die within two days of birth due to hypoactivity and aphagy [127], phenotypes remarkably similar to dopamine deficient mice [130]. Nurr1 heterozygous mice develop normally and generate dopaminergic neurons, but their dopaminergic cells produce much less dopamine [127], as Nurr1 is critical for controlling the expression of tyrosine hydroxylase [50]. The two mutations in exon 1 are in the 5'-UTR (Untranslated Region) of the gene. These mutations result in marked reduction in the expression level of NR4A2/Nurr1 in affected individuals. Previous studies have also found that a homozygous polymorphism in intron 6 of NR4A2 occurs significantly more frequently in familial PD than in sporadic PD [124]. Mutations in exon 1 and exon 3 of NR4A/Nurr1 are also associated with schizophrenia $[12,16]$ and manic depression [12], neuropsychiatric disorders related to dysfunction of mesolimbic and mesocortical dopaminergic pathways. On the other hand, a recent report shows that point mutations in exon 1 of NR4A2 are not present in 44 cases of familial PD cases [131]. More studies are needed to establish the role of NR4A2 mutations in Parkinson's disease.

In addition to NR4A2/Nurr1, other transcription factors such as the LIM homeodomain transcription factor Lmx1b [109] and the homeobox gene Ptx3 [110] are critically involved in the development of mesencephalic dopaminergic neurons. In Lmx1b knockout mice, $\mathrm{TH}^{+}$neurons are produced, but are lost later during development [109]. In the initial population of $\mathrm{TH}^{+}$neurons, Ptx3 is not expressed, suggesting that Lmx1b, together with Ptx3, may play an essential role in the survival of dopaminergic neurons [109]. It is perhaps worthwhile to examine these two genes in PD patients to see if there is any mutation.

\section{II.F. Susceptibility Genes in Sporadic PD}

In the typical sporadic forms of PD, the relative risk for first-degree relatives is at least two to three times that of matched controls [74, 90], which suggests a genetic contribution to idiopathic PD. Several genes have been implicated in sporadic form of PD. These include debrisoquine 4-hydroxylase (CYP2D6) [4, 111], monoamine oxidase A (MAO-A) [47], monoamine oxidase B (MAO-B) [64], etc. However, there are also contradictory reports on the lack of involvement of these genes in sporadic PD [29, $36,83]$. In addition to these genes, there are also a few reports on the possible involvement of superoxide dismutase 2 (SOD2) [99, 106] and the cytochrome P450 1A1 gene (CYP1A1) [114] in sporadic PD. Further studies are necessary to find out whether these genes are involved in PD, and if so, their relative contribution to the cause of the disease. As many of these candidate genes are involved in detoxification of harmful substances or metabolism of neurotransmitters, it seems likely that environmental insults may have differential effects on people carrying mutations of these genes, in comparison to normal subjects. The interplay between genetic and environmental factors may ultimately determine each individual's susceptibility to Parkinson's disease.

\section{THE BIOLOGICAL FUNCTIONS OF PARKIN}

\section{III.A. Parkin is a Protein-Ubiquitin E3 Ligase}

Sequence analysis of the parkin protein shows that it has an ubiquitin-like domain in the N-terminus, followed by a linker region that has no obvious sequence homology with any other proteins. Its C-terminal half contains two RING (Really Interesting New Gene) finger domains and a novel IBR (In-Between RING) domain located between the two RING fingers. It has been found that parkin is a proteinubiquitin E3 ligase, which catalyzes the E2-dependent ubiquitination of many substrate proteins [25].

Ubiquitin (Ub) is a highly conserved 76 amino acid protein. It plays a pivotal role in marking proteins for degradation through the ubiquitin-dependent pathway [44, 45]. Protein ubiquitination is an ATP-dependent sequential process in which ubiquitin is first activated by ubiquitinactivating enzymes (E1), then transferred to ubiquitinconjugation enzymes (E2) and finally ligated to protein substrates by ubiquitin ligase (E3). Ubiquitin is joined to the substrate through an isopeptide bond between Gly76 and a 
Lys residue on the substrate. The ubiquitination enzyme complex then adds more ubiquitin in a sequential manner to Lys48 on the preceding Ub moiety of the substrates to produce polyubiquitinated proteins, which are recognized and degraded by the $26 \mathrm{~S}$ proteasome into small peptides of 3-20 residues. These peptides are released into the cytosol, where they are further hydrolyzed to amino acids by peptidases [56].

A variety of cellular processes depend on the precise temporal and spatial expression pattern of key protein components. It has become increasingly clear that ubiquitinand proteasome-dependent proteolysis is an important aspect in the regulation of protein concentration in the cell. For example, ubiquitin-dependent degradation of cyclins makes it possible to control the concentration of cyclins in a rapid and precise manner to regulate cell cycle progression [39, 54]. The great variation in the in vivo half-life of proteins is achieved, at least in part, by the high specificity of the ubiquitination process. Another layer of regulation is the post-translational modification of substrate proteins [55, 103]. For example, I- $\kappa$ B can only be ubiquitinated and rapidly degraded after it is phosphorylated in response to extracellular stimuli. In its unphosphorylated state, I- $\kappa B$ is very stable [17]. The regulation of protein ubiquitination is further complicated by its reversibility. A family of ubiquitin C-terminal hydrolases or isopeptidases remove ubiquitin from proteins that are already ubiquitinated [123]. One of these deubiquitinating enzymes is the brain-specific UCHL1, whose mutation is implicated in a small group of patients with familial PD discussed before.

The precise regulation of protein degradation ensures a dynamic equilibrium of protein concentration as required by the cellular environment. Failure to eliminate ubiquitinated proteins is a key factor in many diseases, including neurodegenerative disorders. For instance, ubiquitinated proteins are found in Lewy bodies in PD. There are also ubiquitinated proteins in neurofibrilliary tangles in Alzheimer's Disease, in intranuclear inclusions in Huntington's Disease, or in late endosome-like organelles in prion encephalopathies [3]. In these situations, ubiquitinated proteins form aggregates and progressive cell death occurs, although the underlying mechanisms are not fully understood.

\section{III.B. Substrates of Parkin}

Mutations of the parkin gene appear to be recessive in most cases, and many of these mutants exhibited significantly decreased E3 ligase activity. Thus, it is likely that accumulation of parkin substrates may cause degeneration of dopaminergic neurons in SNpc. Parkin is widely expressed in a variety of tissues, including brain, heart, skeletal muscle, lung, kidney, testis, etc. [57]. In the brain, parkin is expressed in almost all regions and there is no significant difference in its expression level in neurons and glial cells, or between dopaminergic neurons and nondopaminergic neurons [98]. However, mutations of the gene in AR-JP patients appear to cause only Parkinson's disease. The key issue is why the loss of function for parkin specifically leads to degeneration of nigral dopaminergic neurons, while other types of cells seem to be unaffected. The working hypothesis is that parkin may have specific substrates in nigral DA neurons; the failure to ubiquitinate and degrade them in the absence of functional parkin may result in their accumulation and ensuing cell death. To test this hypothesis, many groups have performed yeast twohybrid screening to identify the substrates of parkin.

\section{III.B.1. CDCrel-1}

The first substrate found is CDCrel-1 [128], a member of the septin family GTPases that binds to syntaxin-1 [7], but appears to be dispensable in neurotransmitter release, as evidenced by the CDCrel-1 knockout mice [91]. No significant defect is observed in neuronal development and function in CDCrel-1 knockout mice [91]. Subsequent studies using the knockout mice have shown that CDCrel-1 has a non-redundant function in the regulation of platelet secretion [28].

\section{III.B.2. Pael Receptor (Parkin-associated Endothelin Receptor-like Receptor)}

Another substrate of parkin is Pael receptor (Pael-R), a homolog of endothelin receptor type B that is widely expressed in oligodendrocytes in the brain, but generally not in neurons. However, dopamine neurons in SNpc express Pael-R, in contrast to other types of neurons [49]. Overexpression of Pael-R in dopaminergic neuroblastoma cell line SH-SY5Y induces unfolded protein stress (UPS) and cell death. Co-expression of wild-type parkin, but not its PD-linked mutants, suppresses the toxicity of Pael-R. In postmortem brain tissues from AR-JP patients lacking parkin expression, there is significant increase of Pael-R in the Triton X-100-insoluble fraction. These results suggest that the accumulation of Pael-R in nigral DA neurons in the absence of parkin may cause selective degeneration of these neurons [49]. This hypothesis is tested in transgenic flies expressing human Pael-R, which exhibit specific loss of dorsomedial DA neurons. Transgenic flies expressing both parkin and Pael-R show significant reduction in the loss of DA neurons [125]. These studies have demonstrated that Pael-R is probably a key substrate of parkin in nigral DA neurons. It is unclear why overexpression of Pael- $R$ is particularly toxic to DA neurons, compared to other types of cell, e.g. oligodendrocytes.

\section{III.B.3. O-glycosylated $\alpha$-synuclein and Synphilin-1}

Two proteins related to $\alpha$-synuclein have been found to be substrates of parkin. One of them is an O-glycosylated form of $\alpha$-synuclein [108], the other is the $\alpha$-synucleinbinding protein, synphilin-1 [19]. Although $\alpha$-synuclein itself does not interact with parkin, an O-glycosylated form $(\alpha \operatorname{Sp} 22)$ binds to parkin, but not its PD-linked mutants. Furthermore, $\alpha \operatorname{Sp} 22$ is ubiquitinated by wild-type parkin and is accumulated in a non-ubiquitinated form in PD brain tissues lacking parkin expression [108]. These results suggest that the $\mathrm{O}$-glycosylated form of $\alpha$-synuclein is a key substrate of parkin, and its accumulation in the absence of parkin may contribute to the selective degeneration of nigral DA neurons.

However, the existence of O-glycosylated $\alpha$-synuclein in the brain is subject to debate [38]. The major species of $\alpha$ synuclein is not glycosylated, and has been demonstrated not 
to be a substrate of parkin [108]. Instead, the $\alpha$-synucleininteracting protein synphilin-1 binds to parkin and is ubiquitinated by wild-type, but not mutant parkin [19]. Coexpression of $\alpha$-synuclein, synphilin- 1 and parkin in HEK293 cells produces Lewy body-like intracellular inclusions that are ubiquitin-positive. This effect is significantly abrogated by PD-associated mutations of parkin [19].

Although the two studies above identified different substrates of parkin, both results suggest a critical role of parkin in the formation of Lewy bodies. When the parkin gene is mutated, neither $\alpha \mathrm{Sp} 22$ nor synphilin-1 can be effectively ubiquitinated and degraded. These nonubiquitinated parkin substrates may not be able to form Lewy bodies, but appear to be quite toxic to DA neurons, nevertheless. In contrast, parkin, $\alpha$-synuclein, synphilin-1 and ubiquitinated proteins are all found in Lewy bodies in sporadic cases of PD [19, 102], suggesting that ubiquitinated parkin substrates are accumulated in Lewy bodies.

The interaction between $\alpha$-synuclein and parkin has been demonstrated functionally in transgenic flies and cultured mouse neurons. Expression of human parkin in dorsomedial DA neurons in drosophila significantly attenuates the toxicity caused by transgenic expression of either wild-type or mutant human $\alpha$-synuclein [125]. In mouse primary midbrain cultures, Herpes Simplex Virus-mediated expression of $\alpha$-synuclein A53T mutant preferentially kills $\mathrm{TH}^{+}$neurons. Co-expression of parkin significantly mitigates the toxicity of mutant $\alpha$-synuclein [92].

\section{III.B.4. Cyclin E}

More recently, parkin is found to be a component of a large SCF-like ubiquitin ligase complex. By interacting with hSel-10 and Cul1, parkin can ubiquitinate cyclin E, which is recruited to this complex by hSel-10 [112]. Consistent with this observation, cyclin $\mathrm{E}$ is accumulated in substantia nigra of AR-JP brains lacking parkin expression. However, in two sporadic cases of PD, cyclin E expression level appears to be similar to that in AR-JP, but much higher than in normal control or in Alzheimer's disease (AD) [112]. It suggests that the accumulation of cyclin $\mathrm{E}$ may have a direct correlation with PD-associated degeneration of substantia nigra, rather than with the loss of parkin. On the other hand, accumulation of cyclin D1 is observed in SN from AD brains, but not in normal or PD brains [112]. These observations support the idea that abnormal expression of cyclins in postmitotic neurons may trigger apoptosis [23]. Expression of parkin in cerebella granule cells reduces the level of cyclin $E$ and protects these cells from kainate-induced apoptosis. Furthermore, suppression of parkin expression by siRNA potentiates kainate toxicity in cultured DA neurons, while parkin overexpression protects DA neurons from kainateinduced cell death [112].

\section{III.B.5. $\alpha$-tubulin and $\beta$-tubulin}

Our recent studies demonstrate that parkin binds to microtubules very strongly, probably through a direct interaction with $\alpha / \beta$ tubulin heterodimers, the building blocks of microtubules [98]. We have found that almost all parkin is bound to microtubules, as shown in taxol-mediated microtubule co-assembly assays. In contrast to typical microtubule-associated proteins (MAPs), parkin cannot be dissociated from polymerized microtubules at very high salt conditions (up to $4 \mathrm{M}$ of $\mathrm{NaCl}$ ). We were able to disrupt the interaction between parkin and microtubules with $1 \mathrm{M}$ of urea. However, at this condition, microtubules were also destroyed and released $\alpha$ - and $\beta$-tubulin into the supernatant (Yang, F., Zhao, J., Ren, Y., Feng, J., unpublished observations) $^{*}$. The extremely tight interaction between parkin and microtubules is further confirmed by strong coimmunoprecipitation between parkin and $\alpha / \beta$ tubulin heterodimers, as well as subcellular co-localization studies. With a mono-specific antibody against parkin, we have shown that parkin exhibits punctate subcellular localization along microtubules in a variety of cells, including neurons and glial cells in rat brain sections and cultures, human dopaminergic neuroblastoma cell lines, as well as mouse fibroblast cell lines such as 3T3. The parkin-microtubule interaction is further substantiated by the observation that disruption of microtubules by drugs such as colchicine changes the subcellular localization of parkin into a diffusely cytosolic pattern, just like what happens to microtubules [98]. The binding between parkin and $\alpha / \beta$ tubulin appears to be much stronger than its interaction with other proteins.

We have also shown that overexpression of parkin in HEK293 cells increases the ubiquitination and degradation of $\alpha$ - and $\beta$-tubulins, and this effect is significantly abrogated by PD-linked mutations of parkin. Furthermore, similarly ubiquitinated $\alpha$ - and $\beta$-tubulins have been found in rat brain lysates. Taken together, our data suggest that parkin is an E3 ligase for $\alpha$ - and $\beta$-tubulin [98].

Several lines of evidence indicate that tubulin degradation may be involved in Parkinson's disease. Both ubiquitin [72, 78] and tubulin [34] are major components of Lewy bodies, which suggests that ubiquitinated tubulin may be present in them. In addition, two PD-causing neurotoxins, 1-methyl-4phenylpyridinium $\left(\mathrm{MPP}^{+}\right)$and rotenone strongly depolymerize microtubules in vivo and in vitro $[11,13,14,75]$. As depolymerization of microtubules triggers rapid degradation of tubulin [20], the cellular mechanism for degrading tubulin in response to neurotoxins may play a role in PD.

\section{III.B.6. Expanded Polyglutamines}

The most recently reported substrate of parkin up to the writing of this review is the polyglutamine (PolyQ) stretches found in many neurodegenerative disorders [116]. Parkin preferentially binds to expanded PolyQ (e.g. Q79), compared to shorter PolyQ (e.g. Q26). This interaction appears to recruit parkin to huntingtin aggregates in the cytosol and nucleus in transgenic mice expressing a mutant huntingtin gene with 72 glutamines, although parkin is normally not in the nucleus. Parkin increases the in vitro ubiquitination of GFP-Q79 and its degradation in HEK293 cells. This activity reduces the toxicity of GFP-Q79 by decreasing its aggregation and ensuing activation of caspase-12. The interaction between parkin and PolyQ is enhanced by the heat shock protein Hsp70, which binds to the RING-IBR-

\footnotetext{
* Yang, F., Zhao, J., Ren, Y., Feng, J. (2003) Tubulin-binding Domains of Parkin. Soc. Neurosci. Abs. Submitted.
} 
RING region of parkin. On the other hand, the ubiquitin-like (Ubl) domain of parkin binds to the $26 \mathrm{~S}$ proteasome. This study suggests an intriguing model in which parkin could efficiently ubiquitinate mutant proteins containing expanded PolyQ with the help of Hsp70, and then passes the polyubiquitinated substrates directly to the $26 \mathrm{~S}$ proteasome. Functionally, it means that parkin may play an important role in handling expanded PolyQ-containing proteins, which cause a variety of neurodegenerative disorders.

\section{III.C. Animal Models}

As almost all human parkin mutations are recessive, it is reasonable to assume that the lost of function of this gene causes Parkinson's disease. To establish the causative link, many groups have generated parkin mutant mice in which an exon is removed by homologous recombination in embryonic stem cells. There has been no published report on the analysis of these mice.

On the other hand, the drosophila parkin gene has been deleted through imprecise excision of a $P$ element inserted near the parkin locus [41]. The transposable $P$ element was randomly inserted into the drosophila genome. Using a PCRbased screen, a single line of drosophila was identified to harbor a $P$ element inserted $71 \mathrm{bp}$ upstream of the parkin start codon. The $P$ element was then excised under conditions favoring large deletion of flanking sequence, which generated a null allele with the entire parkin locus removed. Although homozygous parkin null flies was also generated, most of the reported phenotypes were obtained from transheterozygous mutants containing the null allele in trans to the $D f(3 L) P c-M K$ deletion chromosome, which has a large deletion spanning the parkin locus. These transheterozygous mutants should not express parkin, although no data was shown to document this important result. The mutants exhibit reduced life span, degeneration of certain muscles, and male sterility due to the lack of mature sperms. The defects in muscle and spermatogenesis are associated with abnormal mitochondria. Transgenic expression of parkin in musculature restores normal morphology of muscles and mitochondria in them; it also rescues flight and climbing problems in the mutants. There is no loss of dopaminergic neurons in these flies, although shrinkage in cell body and reduction of $\mathrm{TH}$ staining in proximal dendrites are consistently observed in dorsomedial DA neurons, but not in other groups of DA neurons. No obvious defect is seen in other parts of the brain.

These results suggest that the presumed loss of parkin in drosophila does not cause significant degeneration of dopaminergic neurons, and that the locomotor problems are caused by mitochondrial defects in muscles, instead. The phenotypes observed in parkin mutant flies differ significantly from those found in AR-JP patients with parkin mutations. If these flies indeed do not express parkin, which is not shown in the paper, it suggests that drosophila parkin may not be a critical factor in the survival of dopaminergic neurons. Thus, the usefulness of these flies in modeling PD may be quite limited. On the other hand, the mitochondrial defects suggest that parkin plays a critical role in normal functions of mitochondria. This is consistent with the recent report that overexpression of parkin in PC12 cells prevents ceramide-induced mitochondrial swelling and cell death [24]. Although further studies are necessary to identify the target(s) of parkin that are important for mitochondrial functions, it seems likely that production of reactive oxygen species by enzymes in mitochondria may be a critical factor in the degeneration of dopamine neurons when parkin is mutated.

In addition to mouse and fly PD models, genetic and pharmacological manipulation of other organisms, such as $C$. elegans, have also produced fruitful results. Wild-type or A53T mutant $\alpha$-synuclein are expressed in $C$. elegans with a pan-neuronal (aex-3), dopaminergic (dat-1) or motor neuron (acr-2) promoter [65]. Both pan-neuronal and dopaminergic expression of either $\alpha$-synuclein cause accelerated degeneration of all three sets of DA neurons, which apparently leads to motor deficits in the worm. No significant difference is observed between wild-type and mutant $\alpha$-synuclein. In contrast, expressing either form of $\alpha$-synuclein under the control of the motor neuron-specific promoter does not cause any significant degeneration of DA neurons [65]. These results suggest that overexpression of human $\alpha$-synuclein, either wild-type or the A53T mutant, induces the selective degeneration of dopaminergic neurons in $C$. elegans. Although the worm does not appear to have its own $\alpha$ synuclein gene, its unique advantages in genetic analysis and apoptosis studies would make it a valuable model organism to study molecular and cellular mechanisms of neurodegeneration and to carry out genetic screens for suppressor and enhancer genes [85].

A pharmacological model of PD in C. elegans has also been made by treating the worm with 6-OHDA, a DA mimetic toxin commonly used to generate mammalian PD models. A brief $(1 \mathrm{~h})$ treatment of $C$. elegans with 6-OHDA $(10 \mathrm{mM})$ leads to death of dopaminergic neurons [86]. The effect is dependent on dopamine transporter (DAT), as coincubation with DAT inhibitors significantly blocks the loss of DA neurons. In addition, 6-OHDA is no longer toxic to $C$. elegans mutants with a deletion of its DAT gene from exon 4 through 12 [86]. The 6-OHDA-induced apoptosis of DA neurons in $C$. elegans is mediated by an unknown pathway that is independent of CED-3 (caspase-9) and CED4 (Apaf-1) [86]. Thus, the 6-OHDA worm model not only recapitulates key features of the mammalian counterparts, but also reveals novel pathways by which the toxin induces apoptosis. Further studies using this model would undoubtedly offer unique and intriguing insights into the molecular and cellular mechanisms underlying the degeneration of DA neurons.

\section{III.D. The Cell Biology of Parkin}

The identification of parkin substrates and the generation of animal models have offered tremendous insights into the biological function of this E3 ligase. It is further complemented by studies that examine where and how it works in the cell.

Depending on the antibodies and experimental approaches, a variety of subcellular localization for parkin has been reported. These include the Golgi apparatus [107], the postsynaptic density [32], synaptic vesicles [63],the 
mitochondria [24], actin filaments [48], etc. Using a monospecific antibody against parkin, we have demonstrated with several independent methods that parkin exhibits punctate localization along microtubules [98]. This observation is further substantiated by our observation that parkin is recruited to the centrosome in a microtubuledependent manner when protein degradation is inhibited in the cell [129]. After dopaminergic neuroblastoma cell lines such as SH-SY5Y or BE(2)c are treated with lactacystin, a specific inhibitor of the $26 \mathrm{~S}$ proteasome, endogenous parkin is accumulated in the centrosome in a manner dependent on the dose and duration of the treatment. Similar observation is made for transfected parkin in HEK293 cells [129] or COS7 cells [53]. The centrosomal recruitment of parkin is accompanied by accumulation of $\gamma$-tubulin in the centrosome. Furthermore, parkin binds to $\gamma$-tubulin in rat brain lysates and in transfected cells [129].

There are two pools of $\gamma$-tubulin in the cell, one in the centrosome and the other in the cytosol. Accumulation of misfolded proteins either by mutation of the gene or by inhibition of the $26 \mathrm{~S}$ proteasome is known to trigger a response that brings $\gamma$-tubulin, chaperones, ubiquitinated proteins and proteasomes, to the centrosome in a microtubule-dependent manner [59]. It appears to represent a concerted response of the cell to bring ubiquitinated protein aggregates to this central location, so it can be degraded by the autophagic pathway [58]. This large inclusion of misfolded and ubiquitinated proteins at the centrosome is contained in a cage formed by intermediate filaments such as vimentin. The structure is termed "aggresome" to differentiate from other types of inclusion bodies formed elsewhere in the cell [59]. The centrosomal recruitment of parkin suggests that it may ubiquitinate its substrates in this specific location. Indeed, substrates such as CDCrel-1, $\alpha$ synuclein and synphilin-1 are accumulated in the centrosome when proteasomes are inhibited [53, 129]. If the ubiquitinated substrates cannot be effectively handled by chaperones and proteasomes that are brought to the centrosome, they may form an aggresome for degradation through autophagy. This pathway seems to be the most efficient way to get rid of misfolded proteins as the burden becomes overwhelming.

However, in cultured neurons, we never observed any significant movement of parkin in response to proteasome inhibitors [129]. In neurons, the relatively small amount of $\gamma$ tubulin is almost exclusively localized in the centrosome [6]. In contrast to mitotic cells, microtubules are not anchored on the centrosome, although they are still nucleated from $\gamma$ tubulin in the centrosome [126]. Soon after the polymerization of a microtubule, it is severed by katanin from the centrosome, released into the cytosol and transported along existing microtubules to where it is needed [5]. The lack of a centrosomally-anchored microtubule network perhaps makes it impossible for protein aggregates to travel to the centrosome, which may cause the formation of inclusion bodies at different sites. This could make neurons more vulnerable to misfolded protein stress than mitotic cells, especially in that neurons cannot divide and would accumulate much more misfolded proteins during their life time. The lack of functional parkin in AR-JP patients would further exacerbate the situation by not ubiquitinating its substrates, such as $\alpha$-synuclein, which appears to be more toxic in dopaminergic neurons than in other neurons.

\section{III.E. A Working Model on the Functions of Parkin}

As illustrated in Fig. (1), aggregates of proteins, such as $\alpha$-synuclein and Pael-R, may overwhelm the 26S proteasome, induce misfolded protein stress and contribute to cell death. By ubiquitinating these substrates, parkin facilitates their degradation and alleviates the stress. When parkin is mutated, accumulation of the substrates specifically kills dopaminergic neurons. The key question is how dopaminergic neurons are selectively affected.

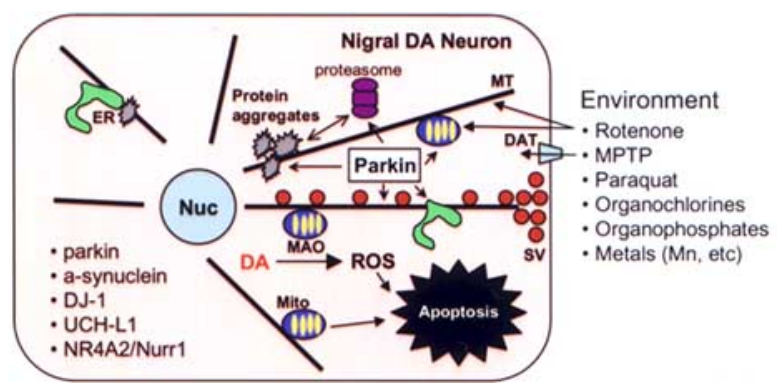

Fig (1). A Working Model for the Functions of Parkin in Dopaminergic Neurons. As the most prevalent genetic factors among the five genes linked to Parkinson's disease, parkin protects dopaminergic neurons through multiple mechanisms. The ability of parkin to ubiquitinate and degrade misfolded tubulin ensures microtubule integrity, which is critical for the transport of dopamine synaptic vesicles. Environmental toxins such as rotenone and MPTP not only inhibit complex I of mitochondria respiratory chain, but also depolymerize microtubules. The latter action may cause accumulation of dopamine vesicles in the cell body and an increase in cytosolic dopamine concentration, which would lead to overproduction of reactive oxygen species due to dopamine oxidation by MAO. As an ubiquitin E3 ligase, parkin facilitates the ubiquitination and degradation of protein aggregates by the $26 \mathrm{~S}$ proteasome. The attachment of ER and mitochondria on microtubules provides the proximity between parkin and its substrates in these organelles, which are retrotranslocated to the cytosol for ubiquitination and degradation. In summary, the combination of misfolded protein stress and oxidative stress may render dopaminergic neurons more vulnerable than other cells. By reducing these stresses, parkin may keep DA neurons from apoptosis. Mutation of the gene or environmental insults may tip the balance and result in the degeneration of these neurons. SV, synaptic vesicle; DAT, dopamine transporter; MT, microtubule; Mito, mitochondria; DA, dopamine; MAO, monoamine oxidase; ROS, reactive oxygen species; Nuc, nucleus; ER, endoplasmic reticulum.

One critical factor for the selectivity could be dopamine itself. The enzymatic oxidation of dopamine by monoamine oxidases (MAO) produces $\mathrm{H}_{2} \mathrm{O}_{2}$, which can be converted to other reactive oxygen species or reactive nitrogen species [51]. These oxyradicals covalently modify many cellular components, such as lipid, enzymes, and DNA. The ensuing oxidative damages significantly affect normal functions of the cell, especially those in the mitochondria, as both MAO- 
A and MAO-B are attached to the mitochondrial outer membrane. Since the mitochondrion is both a cellular power plant (ATP production) and a trigger for apoptosis (cytochrome $\mathrm{C}$ release), its dysfunction would lead to widespread cellular crises that may culminate in cell death. Interestingly, PD-causing neurotoxins, such as MPTP and rotenone, also target mitochondria. Their ability to inhibit complex I results in the uncoupling of the electron transfer chain, which would produce reactive oxygen species as electrons are diverted to water.

As mitochondria are attached to the microtubule network in the cell, it is possible that parkin, by way of its tight association with microtubules [98], may efficiently ubiquitinate damaged or misfolded mitochondrial proteins due to oxidative modification. Parkin may also directly interact with mitochondria to maintain its structural stability [24]. On the other hand, the entire endoplasmic reticulum is also anchored on microtubules. Misfolded ER proteins, such as Pael-R, are retrotranslocated into the cytosol for ubiquitination and degradation [49]. The localization of parkin on microtubules could significantly facilitate the ubiquitination reaction due to the proximity of substrates. In addition, misfolded proteins tend to form aggregates, which are transported along the microtubule network to a central location [59]. The ability of parkin to accumulate in the same inclusion body offers increased efficiency for the E3 ligase to ubiquitinate its substrates [53, 129]. Parkin also interacts with proteasomal components and may thus pass ubiquitinated substrates directly to the protein degradation machinery [116].

Rotenone and $\mathrm{MPP}^{+}$depolymerize microtubules [11, 13] and may prevent the effective transportation of dopamine synaptic vesicles. Accumulation of these leaky vesicles in the cell body may raise cytosolic DA concentration, leading to increased production of reactive oxygen species due to dopamine oxidation by MAO. The interaction between parkin and $\alpha / \beta$ tubulin may be critical for the quality control of the microtubule building blocks. By ubiquitinating and degrading misfolded tubulin [98], parkin may help to keep the rest of the tubulin pool in a polymerization-competent state, thus maintaining the integrity of the microtubule network.

In summary, complicated interactions between unfolded protein stress and oxidative stress may underlie the vulnerability of dopaminergic neurons. Many environmental toxins selectively impact on DA neurons to exacerbate the stress. Parkin protects dopaminergic neurons by ubiquitinating and degrading harmful substrates to reduce both unfolded protein stress and oxidative stress.

\section{NEUROPHARMACOLOGICAL IMPLICATIONS}

The identification of genes linked to familial forms of Parkinson's disease offers great opportunities to develop novel therapeutic strategies for PD. As parkin and $\alpha$ synuclein are by far the best-studied genes in PD, I will focus my attention on them.

\section{A. Pharmacological Targets on $\alpha$-synuclein}

The most important features of $\alpha$-synuclein pertaining to Parkinson's disease are its enrichment in Lewy bodies and its selective toxicity to dopaminergic neurons. At present, although it is still unclear whether Lewy bodies are a cause or an effect of Parkinson's disease, many lines of evidence seem to support the former. The two mutations found in $\alpha$ synuclein have been shown to enhance the formation of $\alpha$ synuclein fibrillar aggregates [84], which are insoluble in $1 \%$ Triton X-100, and very similar to $\alpha$-synuclein found in Lewy bodies. The fact that these two mutations are linked to PD suggests that increased formation of $\alpha$-synuclein-containing inclusions is a causative factor of PD. This is corroborated by $\alpha$-synuclein transgenic flies and mice, in which $\alpha$ synuclein- and ubiquitin-positive Lewy body-like structures are linked to specific degeneration of dopaminergic neurons $[33,76]$. Furthermore, reactive oxygen species (ROS) and reactive nitrogen species (RNS) produced in DA neurons modify $\alpha$-synuclein and accelerate its aggregation [37]. The $\alpha$-synuclein-binding protein, synphilin-1, also enhance the formation of $\alpha$-synuclein aggregates [18].

Based on these findings, one obvious strategy is to reduce the formation of $\alpha$-synuclein aggregates. Antioxidants would reduce oxidative stress in a non-specific manner, which could reduce the formation of $\alpha$-synuclein aggregates. However, ROS and RNS appear to modulate, rather than mediate aggregate formation. To target $\alpha$ synuclein aggregates directly, it is necessary to design small compounds that block the formation of aggregates. Successful precedents have been demonstrated in the ability of Congo red to block the oligomerization of amyloid fibrils, as well as polyglutamines [101]. Infusion of Congo red in huntingtin transgenic mice markedly reduces protein aggregates, and enhances animal survival and motor functions [101]. Congo red preferentially binds to $\beta$-sheets, which are predicted to be enriched in $\alpha$-synuclein as well [31]. It would be interesting to test the effect of Congo red on $\alpha$-synuclein aggregates and $\alpha$-synuclein transgenic animals.

Clearly, the lack of 3D structure significantly hampers rational design of inhibitors. High-throughput assays could be deployed to screen for compounds that block the formation of $\alpha$-synuclein aggregates. On the other hand, efforts could also be directed at inhibiting the binding between $\alpha$-synuclein and synphilin-1, which appears to promote aggregate formation. In addition, one can also exploit the ability of $\beta$-synuclein and $\gamma$-synuclein to inhibit $\alpha$-synuclein fibril formation [117]. It is necessary to characterize in detail how $\alpha$-synuclein interacts with these promoters (e.g. synphilin-1) and inhibitors (e.g. $\beta$ - and $\gamma$ synuclein) of its aggregation. Knowledge gained from such studies could then be used to design effective assays to screening for small compounds that block the formation of $\alpha$-synuclein aggregates or enhance their dissolution.

\section{B. Pharmacological Targets on Parkin}

As parkin appears to be the most important genetic factor in PD, it would probably be very fruitful to search for pharmacological targets that act on parkin. Of particular importance is the interaction between parkin and its various substrates. Although a direct interaction between parkin and $\alpha$-synuclein is still debatable, it is critical to elucidate their interaction, especially when synphilin-1 is also present. Without a detailed knowledge, it would be difficult to 
explore various ways to enhance the degradation of $\alpha$ synuclein or synphilin-1 by parkin.

As overexpression of parkin in drosophila protects the specific toxicity of Pael-R or $\alpha$-synuclein on dorsomedial dopaminergic neurons, it would be very interesting to see whether similar effects can be observed in transgenic mice. If so, enhancing parkin expression by increasing its transcription or decreasing its own degradation would be a very attractive approach. The parkin locus, which is more than 1.3 Mb in length, is one of the largest genes in the human genome. There is evidence that its transcription is regulated by a small bi-directional promoter located between the parkin gene and the PACRG gene (Parkin Co-Regulated Gene), which are only 200 bp apart [122]. At present, it is unknown whether the transcription rate of parkin could be regulated by any factors. Parkin, as well as PACRG, is expressed in a variety of tissues. There is no obvious correlation between the expression patterns of these two genes. Further studies are necessary to investigate the transcription regulation of parkin. The correct splicing of its huge primary transcripts may also be subject to regulation.

The interaction between parkin and tubulins offers novel insights into the function of the gene and potential targets for therapies. Parkin binds to $\alpha / \beta$ tubulin with extremely high affinity, which suggests that all parkin molecules in the cell are associated with tubulins, either in heterodimers or in microtubules. Although it is unclear whether parkin affects the stability of $\alpha / \beta$ heterodimers or the dynamic properties of their polymerization, our preliminary experiments showed that it is virtually impossible to separate parkin from tubulin heterodimers without denaturing them. It is an intriguing possibility that parkin may perform its functions in the context of microtubules, which serves as anchorage and transportation tracks for many organelles including the ER, mitochondria, and synaptic vesicles. Thus, parkin substrates such as Pael-R may be retrotranslocated from the ER, which is attached on the microtubule, for immediate ubiquitination by parkin bound on microtubules.

PD-causing toxins, such as rotenone and $\mathrm{MPP}^{+}$, strongly depolymerize microtubules, which may pose greater risks to dopaminergic neurons than to other neurons. With very long axons, DA neurons in $\mathrm{SN}$ transport dopamine vesicles along microtubules to terminals in striatum. Destroying microtubules by rotenone or $\mathrm{MPP}^{+}$would block vesicle transportation, which results in accumulation of vesicles and ensuing increase in cytosolic DA concentration, due the leakiness of vesicles. Oxidation of dopamine by monoamine oxidases (MAO) produces reactive oxygen species, which is also produced by inhibition of complex I by both toxins. The combined effects may selectively kill dopamine neurons. Our preliminary experiments using rotenone and various inhibitors strongly support the above hypothesis (Ren, Y., Feng, J., unpublished observation) ${ }^{*}$. Thus, a variety of drugs that stabilize microtubules could be tested to see if they have protective functions on DA neurons in cultures or in animal models. When these compounds are combined with anti-

\footnotetext{
* Ren, Y., Feng, J. (2003) Two Sites of Action for Rotenone in the Selective Death of Dopaminergic Neurons. Soc. Neurosci. Abs. Submitted.
}

oxidants or MAO inhibitors, greater protection may be achieved. This approach may circumvent problems associated with old strategies that use MAO inhibitors alone in the treatment of PD. The combination of different drugs may allow for lower dosages of individual components to avoid dangerous side effects on peripheral systems.

The involvement of microtubules in neurodegenerative disorders is a concept strengthened by increasing evidence from disparate lines of research. For example, tau, a microtubule-associated protein has long been recognized as a key factor in Alzheimer's disease, as well as in certain forms of Parkinson's disease. A point mutation in tubulin-specific folding cofactor $\mathrm{E}$ is responsible for progressive motor neuronopathy in mice [9]. Although cofactor $\mathrm{E}$ is presumably required for the correct folding and formation of $\alpha / \beta$ heterodimers in all cells, its mutation selectively affects motor neurons, which also have very long axons that are enriched in microtubules. In an analogous manner, the interaction between parkin and tubulin/microtubules may play a specific role in PD. Further studies are necessary to elucidate the molecular and cellular mechanisms involved. Such studies would also provide new targets for the treatment of neurodegenerative disorders including Parkinson's disease.

\section{CONCLUSION}

In this review, I have summarized recent discoveries of genes that are linked to Parkinson's disease. Special emphasis has been placed on $\alpha$-synuclein and parkin, which are better characterized than other genes such as DJ-1, UCHL1 or NR4A2/Nurr1. From many different lines of studies, it is clear that overexpression of $\alpha$-synuclein, particularly its mutant forms, leads to the formation of aggregates, which may selectively kill dopaminergic neurons. On the other hand, parkin serves to ubiquitinate a variety of substrates to facilitate their degradation. Accumulation of these substrates, e.g. Pael-R, specifically kills dopaminergic neurons. The most critical question unsolved yet is how dopaminergic neurons are selectively damaged. Studies that try to address this question would undoubtedly reveal intriguingly unique features of these neurons.

The exciting developments in the identification of genes linked to PD are producing rapid progress in understanding molecular and cellular mechanisms of this disorder. Elucidation of the functions of these genes, combined with the generation of various genetic models in animals would significantly accelerate the development of novel therapeutic strategies. It is now clear that mutations of a single gene can cause Parkinson's disease. Once we understand more about these individual PD genes, the more challenging tasks are to figure out how PD-linked genes impact on various aspects of dopaminergic neurons in $\mathrm{SNpc}$, how these features are also affected by environmental toxins, and eventually, how new drugs can be developed to prevent or attenuate the degenerative process.

\section{ACKNOWLEDGEMENT}

Our work is supported by NIH grant NS41722 (J. Feng) and Howard Hughes Medical Institute Biomedical Research Support Program grant 53000261 (SUNY-Buffalo). 


\section{REFERENCES}

[1] Abbas, N., Lucking, C.B., Ricard, S., Durr, A., Bonifati, V., De Michele, G., Bouley, S., Vaughan, J.R., Gasser, T., Marconi, R., Broussolle, E., Brefel-Courbon, C., Harhangi, B.S., Oostra, B.A., Fabrizio, E., Bohme, G.A., Pradier, L., Wood, N.W., Filla, A., Meco, G., Denefle, P., Agid, Y., Brice, A. (1999) A wide variety of mutations in the parkin gene are responsible for autosomal recessive parkinsonism in Europe. French Parkinson's Disease Genetics Study Group and the European Consortium on Genetic Susceptibility in Parkinson's Disease. Hum. Mol. Genet., 8, 567574.

[2] Abeliovich, A., Schmitz, Y., Farinas, I., Choi-Lundberg, D., Ho, W.H., Castillo, P.E., Shinsky, N., Verdugo, J.M., Armanini, M., Ryan, A., Hynes, M., Phillips, H., Sulzer, D., Rosenthal, A. (2000) Mice lacking alpha-synuclein display functional deficits in the nigrostriatal dopamine system. Neuron, 25, 239-252.

[3] Alves-Rodrigues, A., Gregori, L., Figueiredo-Pereira, M.E. (1998) Ubiquitin, cellular inclusions and their role in neurodegeneration. Trends Neurosci., 21, 516-520.

[4] Armstrong, M., Daly, A.K., Cholerton, S., Bateman, D.N., Idle, J.R. (1992) Mutant debrisoquine hydroxylation genes in Parkinson's disease. Lancet, 339, 1017-1018.

[5] Baas, P.W. (1999) Microtubules and neuronal polarity: lessons from mitosis. Neuron, 22, 23-31.

[6] Baas, P.W., Joshi, H.C. (1992) Gamma-tubulin distribution in the neuron: implications for the origins of neuritic microtubules. J. Cell Biol., 119, 171-178.

[7] Beites, C.L., Xie, H., Bowser, R., Trimble, W.S. (1999) The septin CDCrel-1 binds syntaxin and inhibits exocytosis. Nat. Neurosci., 2, 434-439.

[8] Betarbet, R., Sherer, T.B., MacKenzie, G., Garcia-Osuna, M., Panov, A.V., Greenamyre, J.T. (2000) Chronic systemic pesticide exposure reproduces features of Parkinson's disease. Nat. Neurosci., 3, 1301-1306.

[9] Bommel, H., Xie, G., Rossoll, W., Wiese, S., Jablonka, S., Boehm, T., Sendtner, M. (2002) Missense mutation in the tubulin-specific chaperone $\mathrm{E}$ (Tbce) gene in the mouse mutant progressive motor neuronopathy, a model of human motoneuron disease. J. Cell Biol., 159, 563-569.

[10] Bonifati, V., Rizzu, P., van Baren, M.J., Schaap, O., Breedveld, G.J., Krieger, E., Dekker, M.C.J., Squitieri, F., Ibanez, P., Joosse, M., van Dongen, J.W., Vanacore, N., van Swieten, J.C., Brice, A., Meco, G., van Duijn, C.M., Oostra, B.A., Heutink, P. (2003) Mutations in the DJ-1 Gene Associated with Autosomal Recessive Early-Onset Parkinsonism. Science, 299, 256-259.

[11] Brinkley, B.R., Barham, S.S., Barranco, S.C., Fuller, G.M. (1974) Rotenone inhibition of spindle microtubule assembly in mammalian cells. Exp. Cell Res., 85, 41-46.

[12] Buervenich, S., Carmine, A., Arvidsson, M., Xiang, F., Zhang, Z., Sydow, O., Jonsson, E.G., Sedvall, G.C., Leonard, S., Ross, R.G., Freedman, R., Chowdari, K.V., Nimgaonkar, V.L., Perlmann, T., Anvret, M., Olson, L. (2000) NURR1 mutations in cases of schizophrenia and manic-depressive disorder. Am. J. Med. Genet., 96, 808-813.

[13] Cappelletti, G., Maggioni, M.G., Maci, R. (1999) Influence of $\mathrm{MPP}+$ on the state of tubulin polymerisation in NGF- differentiated PC12 cells. J. Neurosci. Res., 56, 28-35.

[14] Cappelletti, G., Pedrotti, B., Maggioni, M.G., Maci, R. (2001) Microtubule assembly is directly affected by $\mathrm{MPP}(+)$ in vitro. Cell Biol. Int., 25, 981-984.

[15] Chan, P., Tanner, C.M., Jiang, X., Langston, J.W. (1998) Failure to find the alpha-synuclein gene missense mutation (G209A) in 100 patients with younger onset Parkinson's disease. Neurology, 50, 513-514.

[16] Chen, Y.H., Tsai, M.T., Shaw, C.K., Chen, C.H. (2001) Mutation analysis of the human NR4A2 gene, an essential gene for midbrain dopaminergic neurogenesis, in schizophrenic patients. Am. J. Med. Genet., 105, 753-757.

[17] Chen, Z., Hagler, J., Palombella, V.J., Melandri, F., Scherer, D., Ballard, D., Maniatis, T. (1995) Signal-induced site-specific phosphorylation targets I kappa B alpha to the ubiquitin-proteasome pathway. Genes Dev., 9, 1586-1597.

[18] Chung, K.K., Zhang, Y., Lim, K.L., Tanaka, Y., Huang, H., Gao, J., Ross, C.A., Dawson, V.L., Dawson, T.M. (2001) Parkin ubiquitinates the alpha-synuclein-interacting protein, synphilin-1: implications for Lewy-body formation in Parkinson disease. Nat. Med., 7, 1144-1150.

[19] Chung, K.K., Zhang, Y., Lim, K.L., Tanaka, Y., Huang, H., Gao, J., Ross, C.A., Dawson, V.L., Dawson, T.M. (2001) Parkin ubiquitinates the alpha-synuclein-interacting protein, synphilin-1: implications for Lewy-body formation in Parkinson disease. Nat. Med., 7, 1144-1150.

[20] Cleveland, D.W. (1989) Autoregulated control of tubulin synthesis in animal cells. Curr. Opin. Cell Biol., 1, 10-14.

[21] Conway, K.A., Harper, J.D., Lansbury, P.T. (1998) Accelerated in vitro fibril formation by a mutant alpha-synuclein linked to earlyonset Parkinson disease. Nat. Med., 4, 1318-1320.

[22] Cookson, M.R. (2003) Pathways to Parkinsonism. Neuron 37, 7-10.

[23] Copani, A., Uberti, D., Sortino, M.A., Bruno, V., Nicoletti, F., Memo, M. (2001) Activation of cell cycle-associated proteins in neuronal death: a mandatory or dispensable path? Trends Neurosci., 24, 25-31.

[24] Darios, F., Corti, O., Lucking, C.B., Hampe, C., Muriel, M.P., Abbas, N., Gu, W.J., Hirsch, E.C., Rooney, T., Ruberg, M., Brice, A. (2003) Parkin prevents mitochondrial swelling and cytochrome c release in mitochondria-dependent cell death. Hum. Mol. Genet., 12, 517-526.

[25] Dawson, T.M., Dawson, V.L. (2003) Rare genetic mutations shed light on the pathogenesis of Parkinson disease. J. Clin. Invest., 111, 145-151.

[26] de Nobel, H., Lawrie, L., Brul, S., Klis, F., Davis, M., Alloush, H., Coote, P. (2001) Parallel and comparative analysis of the proteome and transcriptome of sorbic acid-stressed Saccharomyces cerevisiae. Yeast, 18, 1413-1428.

[27] de Rijk, M.C., Tzourio, C., Breteler, M.M., Dartigues, J.F., Amaducci, L., Lopez-Pousa, S., Manubens-Bertran, J.M., Alperovitch, A., Rocca, W.A. (1997) Prevalence of parkinsonism and Parkinson's disease in Europe: the EUROPARKINSON Collaborative Study. European Community Concerted Action on the Epidemiology of Parkinson's disease. J. Neurol. Neurosurg. Psychiatry, 62, 10-15.

[28] Dent, J., Kato, K., Peng, X.R., Martinez, C., Cattaneo, M., Poujol, C., Nurden, P., Nurden, A., Trimble, W.S., Ware, J. (2002) A prototypic platelet septin and its participation in secretion. Proc. Natl. Acad. Sci. USA, 99, 3064-3069.

[29] Diederich, N., Hilger, C., Goetz, C.G., Keipes, M., Hentges, F., Vieregge, P., Metz, H. (1996) Genetic variability of the CYP 2D6 gene is not a risk factor for sporadic Parkinson's disease. Ann. Neurol., 40, 463-465.

[30] Dunnett, S.B., Bjorklund, A. (1999) Prospects for new restorative and neuroprotective treatments in Parkinson's disease. Nature, 399, A32-A39.

[31] El Agnaf, O.M.A., Irvine, G.B. (2000) Review: Formation and properties of amyloid-like fibrils derived from alpha-synuclein and related proteins. J. Struc. Biol., 130, 300-309.

[32] Fallon, L., Moreau, F., Croft, B.G., Labib, N., Gu, W.J., Fon, E.A. (2002) Parkin and CASK/LIN-2 associate via a PDZ-mediated interaction and are co-localized in lipid rafts and postsynaptic densities in brain. J. Biol. Chem., 277, 486-491.

[33] Feany, M.B., Bender, W.W. (2000) A Drosophila model of Parkinson's disease. Nature, 404, 394-398.

[34] Galloway, P.G., Mulvihill, P., Perry, G. (1992) Filaments of Lewy bodies contain insoluble cytoskeletal elements. Am. J. Pathol., 140, 809-822.

[35] Gasser, T. (2001) Genetics of Parkinson's disease. J. Neurol., 248, 833-840.

[36] Gasser, T., Muller-Myhsok, B., Supala, A., Zimmer, E., Wieditz, G., Wszolek, Z.K., Vieregge, P., Bonifati, V., Oertel, W.H. (1996) The CYP2D6B allele is not overrepresented in a population of German patients with idiopathic Parkinson's disease. J. Neurol. Neurosurg. Psychiatry, 61, 518-520.

[37] Giasson, B.I., Duda, J.E., Murray, I.V., Chen, Q., Souza, J.M., Hurtig, H.I., Ischiropoulos, H., Trojanowski, J.Q., Lee, V.M. (2000) Oxidative damage linked to neurodegeneration by selective alphasynuclein nitration in synucleinopathy lesions. Science, 290, 985989.

[38] Giasson, B.I., Duda, J.E., Quinn, S.M., Zhang, B., Trojanowski, J.Q., Lee, V.M. (2002) Neuronal alpha-synucleinopathy with severe 
movement disorder in mice expressing A53T human alphasynuclein. Neuron, 34, 521-533.

[39] Glotzer, M., Murray, A.W., Kirschner, M.W. (1991) Cyclin is degraded by the ubiquitin pathway. Nature, 349, 132-138.

[40] Golbe, L.I., Miller, D., Duvoisin, R.C. (1990) Parkinson's disease: anatomy, pathology and therapy. Strefler, M.R., Korczyn, A.D., Melamed, E., Youdoim, M.G.H. Eds., pp. 287-292, Raven Press, New York.

[41] Greene, J.C., Whitworth, A.J., Kuo, I., Andrews, L.A., Feany, M.B., Pallanck, L.J. (2003) Mitochondrial pathology and apoptotic muscle degeneration in Drosophila parkin mutants. Proc. Natl. Acad. Sci. USA, 100, 4078-4083.

[42] Hattori, N., Kitada, T., Matsumine, H., Asakawa, S., Yamamura, Y., Yoshino, H., Kobayashi, T., Yokochi, M., Wang, M., Yoritaka, A., Kondo, T., Kuzuhara, S., Nakamura, S., Shimizu, N., Mizuno, Y. (1998) Molecular genetic analysis of a novel Parkin gene in Japanese families with autosomal recessive juvenile parkinsonism: evidence for variable homozygous deletions in the Parkin gene in affected individuals. Ann. Neurol., 44, 935-941.

[43] Hattori, N., Matsumine, H., Asakawa, S., Kitada, T., Yoshino, H., Elibol, B., Brookes, A.J., Yamamura, Y., Kobayashi, T., Wang, M., Yoritaka, A., Minoshima, S., Shimizu, N., Mizuno, Y. (1998) Point mutations (Thr240Arg and Gln311Stop) in the Parkin gene. Biochem. Biophys. Res. Commun., 249, 754-758.

[44] Hershko, A., Ciechanover, A. (1998) The ubiquitin system. Annu. Rev. Biochem., 67, 425-479.

[45] Hochstrasser, M. (1996) Ubiquitin-dependent protein degradation. Annu. Rev. Genet., 30, 405-439.

[46] Hod, Y., Pentyala, S.N., Whyard, T.C., El Maghrabi, M.R. (1999) Identification and characterization of a novel protein that regulates RNA-protein interaction. J. Cell Biochem., 72, 435-444.

[47] Hotamisligil, G.S., Girmen, A.S., Fink, J.S., Tivol, E., Shalish, C., Trofatter, J., Baenziger, J., Diamond, S., Markham, C., Sullivan, J. (1994) Hereditary variations in monoamine oxidase as a risk factor for Parkinson's disease. Mov. Disord., 9, 305-310.

[48] Huynh, D.P., Scoles, D.R., Ho, T.H., Del Bigio, M.R., Pulst, S.M. (2000) Parkin is associated with actin filaments in neuronal and nonneural cells. Ann. Neurol., 48, 737-744.

[49] Imai, Y., Soda, M., Inoue, H., Hattori, N., Mizuno, Y., Takahashi, R. (2001) An unfolded putative transmembrane polypeptide, which can lead to endoplasmic reticulum stress, is a substrate of Parkin. Cell, 105, 891-902.

[50] Iwawaki, T., Kohno, K., Kobayashi, K. (2000) Identification of a potential nurr1 response element that activates the tyrosine hydroxylase gene promoter in cultured cells. Biochem. Biophys. Res. Commun., 274, 590-595.

[51] Jenner, P., Olanow, C.W. (1996) Oxidative stress and the pathogenesis of Parkinson's disease. Neurology, 47, S161-S170.

[52] Jeon, B.S., Jacksonlewis, V., Burke, R.E. (1995) 6Hydroxydopamine Lesion of the Rat Substantia-Nigra - TimeCourse and Morphology of Cell-Death. Neurodegeneration, 4, 131137.

[53] Junn, E., Lee, S.S., Suhr, U.T., Mouradian, M.M. (2002) Parkin accumulation in aggresomes due to proteasome impairment. J. Biol. Chem., 277, 47870-47877.

[54] King, R.W., Deshaies, R.J., Peters, J.M., Kirschner, M.W. (1996) How proteolysis drives the cell cycle. Science, 274, 1652-1659.

[55] Kirschner, M. (1999) Intracellular proteolysis. Trends Cell Biol., 9, M42-M45.

[56] Kisselev, A.F., Akopian, T.N., Woo, K.M., Goldberg, A.L. (1999) The sizes of peptides generated from protein by mammalian 26 and $20 \mathrm{~S}$ proteasomes. Implications for understanding the degradative mechanism and antigen presentation. J. Biol. Chem., 274, 33633371.

[57] Kitada, T., Asakawa, S., Hattori, N., Matsumine, H., Yamamura, Y., Minoshima, S., Yokochi, M., Mizuno, Y., Shimizu, N. (1998) Mutations in the parkin gene cause autosomal recessive juvenile parkinsonism. Nature, 392, 605-608.

[58] Klionsky, D.J., Emr, S.D. (2000) Autophagy as a regulated pathway of cellular degradation. Science, 290, 1717-1721.

[59] Kopito, R.R. (2000) Aggresomes, inclusion bodies and protein aggregation. Trends Cell Biol., 10, 524-530.

[60] Kotaja, N., Karvonen, U., Janne, O.A., Palvimo, J.J. (2002) PIAS proteins modulate transcription factors by functioning as SUMO-1 ligases. Mol. Cell. Biol., 22, 5222-5234.
[61] Kowall, N.W., Hantraye, P., Brouillet, E., Beal, M.F., Mckee, A.C., Ferrante, R.J. (2000) MPTP induces alpha-synuclein aggregation in the substantia nigra of baboons. Neuroreport, 11, 211-213.

[62] Kruger, R., Kuhn, W., Muller, T., Woitalla, D., Graeber, M., Kosel, S., Przuntek, H., Epplen, J.T., Schols, L., Riess, O. (1998) Ala30Pro mutation in the gene encoding alpha-synuclein in Parkinson's disease. Nat. Genet., 18, 106-108.

[63] Kubo, S.I., Kitami, T., Noda, S., Shimura, H., Uchiyama, Y., Asakawa, S., Minoshima, S., Shimizu, N., Mizuno, Y., Hattori, N. (2001) Parkin is associated with cellular vesicles. J. Neurochem., 78, 42-54.

[64] Kurth, J.H., Kurth, M.C., Poduslo, S.E., Schwankhaus, J.D. (1993) Association of a monoamine oxidase B allele with Parkinson's disease. Ann. Neurol., 33, 368-372.

[65] Lakso, M., Vartiainen, S., Moilanen, A.M., Sirvio, J., Thomas, J.H., Nass, R., Blakely, R.D., Wong, G. (2003) Dopaminergic neuronal loss and motor deficits in Caenorhabditis elegans overexpressing human alpha-synuclein. J. Neurochem., 86, 165-172.

[66] Langston, J.W., Ballard, P., Tetrud, J.W., Irwin, I. (1983) Chronic Parkinsonism in Humans Due to A Product of Meperidine-Analog Synthesis. Science, 219, 979-980.

[67] Le, W.D., Xu, P.Y., Jankovic, J., Jiang, H., Appel, S.H., Smith, R.G., Vassilatis, D.K. (2003) Mutations in NR4A2 associated with familial Parkinson disease. Nature Genetics, 33, 85-89.

[68] Lee, M.K., Stirling, W., Xu, Y., Xu, X., Qui, D., Mandir, A.S., Dawson, T.M., Copeland, N.G., Jenkins, N.A., Price, D.L. (2002) Human alpha -synuclein-harboring familial Parkinson's diseaselinked Ala-53 right-arrow Thr mutation causes neurodegenerative disease with alpha -synuclein aggregation in transgenic mice. PNAS, 99, 8968 .

[69] Leroy, E., Anastasopoulos, D., Konitsiotis, S., Lavedan, C., Polymeropoulos, M.H. (1998) Deletions in the Parkin gene and genetic heterogeneity in a Greek family with early onset Parkinson's disease. Hum. Genet., 103, 424-427.

[70] Leroy, E., Boyer, R., Auburger, G., Leube, B., Ulm, G., Mezey, E., Harta, G., Brownstein, M.J., Jonnalagada, S., Chernova, T., Dehejia, A., Lavedan, C., Gasser, T., Steinbach, P.J., Wilkinson, K.D., Polymeropoulos, M.H. (1998) The ubiquitin pathway in Parkinson's disease. Nature, 395, 451-452.

[71] Liu, Y., Fallon, L., Lashuel, H.A., Liu, Z., Lansbury, P.T., Jr. (2002) The UCH-L1 gene encodes two opposing enzymatic activities that affect alpha-synuclein degradation and Parkinson's disease susceptibility. Cell, 111, 209-218.

[72] Lowe, J., Blanchard, A., Morrell, K., Lennox, G., Reynolds, L., Billett, M., Landon, M., Mayer, R.J. (1988) Ubiquitin is a common factor in intermediate filament inclusion bodies of diverse type in man, including those of Parkinson's disease, Pick's disease, and Alzheimer's disease, as well as Rosenthal fibres in cerebellar astrocytomas, cytoplasmic bodies in muscle, and mallory bodies in alcoholic liver disease. J. Pathol., 155, 9-15.

[73] Lucking, C.B., Durr, A., Bonifati, V., Vaughan, J., De Michele, G., Gasser, T., Harhangi, B.S., Meco, G., Denefle, P., Wood, N.W., Agid, Y., Brice, A. (2000) Association between early-onset Parkinson's disease and mutations in the parkin gene. N. Engl. J. Med., 342, 1560-1567.

[74] Marder, K., Tang, M.X., Mejia, H., Alfaro, B., Cote, L., Louis, E., Groves, J., Mayeux, R. (1996) Risk of Parkinson's disease among first-degree relatives: A community- based study. Neurology, 47, 155-160.

[75] Marshall, L.E., Himes, R.H. (1978) Rotenone inhibition of tubulin self-assembly. Biochim. Biophys. Acta, 543, 590-594.

[76] Masliah, E., Rockenstein, E., Veinbergs, I., Mallory, M., Hashimoto, M., Takeda, A., Sagara, Y., Sisk, A., Mucke, L. (2000) Dopaminergic loss and inclusion body formation in alpha-synuclein mice: implications for neurodegenerative disorders. Science, 287, 1265-1269.

[77] Matsumine, H., Saito, M., Shimoda-Matsubayashi, S., Tanaka, H., Ishikawa, A., Nakagawa-Hattori, Y., Yokochi, M., Kobayashi, T., Igarashi, S., Takano, H., Sanpei, K., Koike, R., Mori, H., Kondo, T., Mizutani, Y., Schaffer, A.A., Yamamura, Y., Nakamura, S., Kuzuhara, S., Tsuji, S., Mizuno, Y. (1997) Localization of a gene for an autosomal recessive form of juvenile Parkinsonism to chromosome 6q25.2-27. Am. J. Hum. Genet., 60, 588-596.

[78] Mayer, R.J., Lowe, J., Lennox, G., Landon, M., MacLennan, K., Doherty, F.J. (1989) Intermediate filament-ubiquitin diseases: 
implications for cell sanitization. Biochem. Soc. Symp., 55, 193201

[79] Mink, J.W. (1999) Fundamental Neuroscience. Zigmond, M.J., Bloom, F.E., Landis, S.C., Roberts, J.L., Squire, L.R. Eds., pp. 951972 (Academic Press, San Diego, CA).

[80] Mitsumoto, A., Nakagawa, Y. (2001) DJ-1 is an indicator for endogenous reactive oxygen species elicited by endotoxin. Free Radic. Res., 35, 885-893.

[81] Mitsumoto, A., Nakagawa, Y., Takeuchi, A., Okawa, K., Iwamatsu, A., Takanezawa, Y. (2001) Oxidized forms of peroxiredoxins and DJ-1 on two-dimensional gels increased in response to sublethal levels of paraquat. Free Radic. Res., 35, 301-310.

[82] Nagakubo, D., Taira, T., Kitaura, H., Ikeda, M., Tamai, K., IguchiAriga, S.M., Ariga, H. (1997) DJ-1, a novel oncogene which transforms mouse NIH3T3 cells in cooperation with ras. Biochem. Biophys. Res. Commun., 231, 509-513.

[83] Nanko, S., Ueki, A., Hattori, M. (1996) No association between Parkinson's disease and monoamine oxidase A and B gene polymorphisms. Neurosci. Lett., 204, 125-127.

[84] Narhi, L., Wood, S.J., Steavenson, S., Jiang, Y., Wu, G.M., Anafi, D., Kaufman, S.A., Martin, F., Sitney, K., Denis, P., Louis, J.C., Wypych, J., Biere, A.L., Citron, M. (1999) Both familial Parkinson's disease mutations accelerate alpha-synuclein aggregation. J. Biol. Chem., 274, 9843-9846.

[85] Nass, R., Blakely, R.D. (2003) The Caenorhabditis Elegans Dopaminergic System: Opportunities for Insights into Dopamine Transport and Neurodegeneration. Annu. Rev. Pharmacol. Toxicol., 43, 521-544.

[86] Nass, R., Hall, D.H., Miller, D.M., III, Blakely, R.D. (2002) Neurotoxin-induced degeneration of dopamine neurons in Caenorhabditis elegans. Proc. Natl. Acad. Sci. USA, 99, 3264-3269.

[87] Okada, M., Matsumoto, K., Niki, T., Taira, T., Iguchi-Ariga, S.M., Ariga, H. (2002) DJ-1, a target protein for an endocrine disrupter, participates in the fertilization in mice. Biol. Pharm. Bull., 25, 853856.

[88] Olanow, C.W., Tatton, W.G. (1999) Etiology and pathogenesis of Parkinson's disease. Annu. Rev. Neurosci., 22, 123-144.

[89] Oliveira, S.A., Scott, W.K., Martin, E.R., Nance, M.A., Watts, R.L., Hubble, J.P., Koller, W.C., Pahwa, R., Stern, M.B., Hiner, B.C., Ondo, W.G., Allen, F.H., Jr., Scott, B.L., Goetz, C.G., Small, G.W., Mastaglia, F., Stajich, J.M., Zhang, F., Booze, M.W., Winn, M.P., Middleton, L.T., Haines, J.L., Pericak-Vance, M.A., Vance, J.M. (2003) Parkin mutations and susceptibility alleles in late-onset Parkinson's disease. Ann. Neurol., 53, 624-629.

[90] Payami, H., Larsen, K., Bernard, S., Nutt, J. (1994) Increased risk of Parkinson's disease in parents and siblings of patients. Ann. Neurol., 36, 659-661.

[91] Peng, X.R., Jia, Z., Zhang, Y., Ware, J., Trimble, W.S. (2002) The septin CDCrel-1 is dispensable for normal development and neurotransmitter release. Mol. Cell Biol., 22, 378-387.

[92] Petrucelli, L., O'Farrell, C., Lockhart, P.J., Baptista, M., Kehoe, K., Vink, L., Choi, P., Wolozin, B., Farrer, M., Hardy, J., Cookson, M.R. (2002) Parkin protects against the toxicity associated with mutant alpha-synuclein: proteasome dysfunction selectively affects catecholaminergic neurons. Neuron, 36, 1007-1019.

[93] Poewe, W.H., Wenning, G.K. (1998) The natural history of Parkinson's disease. Ann. Neurol., 44, S1-S9.

[94] Polymeropoulos, M.H., Higgins, J.J., Golbe, L.I., Johnson, W.G., Ide, S.E., Di Iorio, G., Sanges, G., Stenroos, E.S., Pho, L.T., Schaffer, A.A., Lazzarini, A.M., Nussbaum, R.L., Duvoisin, R.C. (1996) Mapping of a gene for Parkinson's disease to chromosome 4q21-q23. Science, 274, 1197-1199.

[95] Polymeropoulos, M.H., Lavedan, C., Leroy, E., Ide, S.E., Dehejia, A., Dutra, A., Pike, B., Root, H., Rubenstein, J., Boyer, R., Stenroos, E.S., Chandrasekharappa, S., Athanassiadou, A., Papapetropoulos, T., Johnson, W.G., Lazzarini, A.M., Duvoisin, R.C., Di Iorio, G., Golbe, L.I., Nussbaum, R.L. (1997) Mutation in the alpha-synuclein gene identified in families with Parkinson's disease. Science, 276, 2045-2047.

[96] Przedborski, S., Jackson-Lewis, V. (1998) Mechanisms of MPTP toxicity. Movement Disorders, 13, 35-38.

[97] Rathke-Hartlieb, S., Kahle, P.J., Neumann, M., Ozmen, L., Haid, S., Okochi, M., Haass, C., Schulz, J.B. (2001) Sensitivity to MPTP is not increased in Parkinson's disease-associated mutant alphasynuclein transgenic mice. J. Neurochem., 77, 1181-1184.
[98] Ren, Y., Zhao, J.H., Feng, J. (2003) Parkin binds to alpha/beta tubulin and increases their ubiquitination and degradation. $J$. Neurosci., 23, 3316-3324.

[99] Saggu, H., Cooksey, J., Dexter, D., Wells, F.R., Lees, A., Jenner, P., Marsden, C.D. (1989) A selective increase in particulate superoxide dismutase activity in parkinsonian substantia nigra. $J$. Neurochem., 53, 692-697.

[100] Saigoh, K., Wang, Y.L., Suh, J.G., Yamanishi, T., Sakai, Y., Kiyosawa, H., Harada, T., Ichihara, N., Wakana, S., Kikuchi, T., Wada, K. (1999) Intragenic deletion in the gene encoding ubiquitin carboxy-terminal hydrolase in gad mice. Nat. Genet., 23, 47-51.

[101] Sanchez, I., Mahlke, C., Yuan, J.Y. (2003) Pivotal role of oligomerization in expanded polyglutamine neurodegenerative disorders. Nature, 421, 373-379.

[102] Schlossmacher, M.G., Frosch, M.P., Gai, W.P., Medina, M., Sharma, N., Forno, L., Ochiishi, T., Shimura, H., Sharon, R., Hattori, N., Langston, J.W., Mizuno, Y., Hyman, B.T., Selkoe, D.J., Kosik, K.S. (2002) Parkin localizes to the lewy bodies of Parkinson disease and dementia with lewy bodies. Am. J. Pathol., 160, 16551667.

[103] Schwartz, A.L., Ciechanover, A. (1999) The ubiquitin-proteasome pathway and pathogenesis of human diseases. Annu. Rev. Med., 50, 57-74.

[104] Scott, W.K., Nance, M.A., Watts, R.L., Hubble, J.P., Koller, W.C., Lyons, K., Pahwa, R., Stern, M.B., Colcher, A., Hiner, B.C., Jankovic, J., Ondo, W.G., Allen, F.H., Goetz, C.G., Small, G.W., Masterman, D., Mastaglia, F., Laing, N.G., Stajich, J.M., Slotterbeck, B., Booze, M.W., Ribble, R.C., Rampersaud, E., West, S.G., Gibson, R.A., Middleton, L.T., Roses, A.D., Haines, J.L., Scott, B.L., Vance, J.M., Pericak-Vance, M.A. (2001) Complete genomic screen in Parkinson disease: evidence for multiple genes. JAMA, 286, 2239-2244.

[105] Scott, W.K., Staijich, J.M., Yamaoka, L.H., Speer, M.C., Vance, J.M., Roses, A.D., Pericak-Vance, M.A. (1997) Genetic complexity and Parkinson's disease. Science, 277, 387-388.

[106] Shimoda-Matsubayashi, S., Matsumine, H., Kobayashi, T., Nakagawa-Hattori, Y., Shimizu, Y., Mizuno, Y. (1996) Structural Dimorphism in the Mitochondrial Targeting Sequence in the Human Manganese Superoxide Dismutase Gene. Biochem. Biophys. Res. Commun., 226, 561-565.

[107] Shimura, H., Hattori, N., Kubo, S., Yoshikawa, M., Kitada, T., Matsumine, H., Asakawa, S., Minoshima, S., Yamamura, Y., Shimizu, N., Mizuno, Y. (1999) Immunohistochemical and subcellular localization of Parkin protein: absence of protein in autosomal recessive juvenile parkinsonism patients. Ann. Neurol., 45, 668-672.

[108] Shimura, H., Schlossmacher, M.G., Hattori, N., Frosch, M.P., Trockenbacher, A., Schneider, R., Mizuno, Y., Kosik, K.S., Selkoe, D.J. (2001) Ubiquitination of a new form of alpha-synuclein by parkin from human brain: implications for Parkinson's disease. Science, 293, 263-269.

[109] Smidt, M.P., Asbreuk, C.H., Cox, J.J., Chen, H., Johnson, R.L., Burbach, J.P. (2000) A second independent pathway for development of mesencephalic dopaminergic neurons requires Lmx1b. Nat. Neurosci., 3, 337-341.

[110] Smidt, M.P., van Schaick, H.S., Lanctot, C., Tremblay, J.J., Cox, J.J., van der Kleij, A.A., Wolterink, G., Drouin, J., Burbach, J.P. (1997) A homeodomain gene Ptx3 has highly restricted brain expression in mesencephalic dopaminergic neurons. Proc. Natl. Acad. Sci. USA, 94, 13305-13310.

[111] Smith, C.A., Gough, A.C., Leigh, P.N., Summers, B.A., Harding, A.E., Maraganore, D.M., Sturman, S.G., Schapira, A.H., Williams, A.C., Maranganore, D.M. (1992) Debrisoquine hydroxylase gene polymorphism and susceptibility to Parkinson's disease. Lancet, 339, 1375-1377.

[112] Staropoli, J.F., McDermott, C., Martinat, C., Schulman, B., Demireva, E., Abeliovich, A. (2003) Parkin is a component of an SCF-like ubiquitin ligase complex and protects postmitotic neurons from kainate excitotoxicity. Neuron, 37, 735-749.

[113] Takahashi, K., Taira, T., Niki, T., Seino, C., Iguchi-Ariga, S.M., Ariga, H. (2001) DJ-1 positively regulates the androgen receptor by impairing the binding of PIASx alpha to the receptor. J. Biol. Chem., 276, 37556-37563.

[114] Takakubo, F., Yamamoto, M., Ogawa, N., Yamashita, Y., Mizuno, Y., Kondo, I. (1996) Genetic association between cytochrome 
P450IA1 gene and susceptibility to Parkinson's disease. J. Neural. Transm. Gen. Sect., 103, 843-849.

[115] Tanner, C.M., Langston, J.W. (1990) Do environmental toxins cause Parkinson's disease? A critical review. Neurology, 40, 1-30.

[116] Tsai, Y.C., Fishman, P.S., Thakor, N.V., Oyler, G.A. (2003) Parkin facilitates the elimination of expanded polyglutamine proteins and leads to preservation of proteasome function. J. Biol. Chem., 278, 22044-22055.

[117] Uversky, V.N., Li, J., Souillac, P., Millett, I.S., Doniach, S., Jakes, R., Goedert, M., Fink, A.L. (2002) Biophysical properties of the synucleins and their propensities to fibrillate: inhibition of alphasynuclein assembly by beta- and gamma-synucleins. J. Biol. Chem., 277, 11970-11978.

[118] Vaughan, J., Durr, A., Tassin, J., Bereznai, B., Gasser, T., Bonifati, V., De Michele, G., Fabrizio, E., Volpe, G., Bandmann, O., Johnson, W.G., Golbe, L.I., Breteler, M., Meco, G., Agid, Y., Brice, A., Marsden, C.D., Wood, N.W. (1998) The alpha-synuclein Ala53Thr mutation is not a common cause of familial Parkinson's disease: a study of 230 European cases. European Consortium on Genetic Susceptibility in Parkinson's Disease. Ann. Neurol., 44, 270-273.

[119] Vaughan, J.R., Farrer, M.J., Wszolek, Z.K., Gasser, T., Durr, A., Agid, Y., Bonifati, V., DeMichele, G., Volpe, G., Lincoln, S., Breteler, M., Meco, G., Brice, A., Marsden, C.D., Hardy, J., Wood, N.W. (1998) Sequencing of the alpha-synuclein gene in a large series of cases of familial Parkinson's disease fails to reveal any further mutations. The European Consortium on Genetic Susceptibility in Parkinson's Disease (GSPD). Hum. Mol. Genet., 7, 751-753.

[120] Vila, M., Vukosavic, S., Jackson-Lewis, V., Neystat, M., Jakowec, M., Przedborski, S. (2000) alpha-synuclein up-regulation in substantia nigra dopaminergic neurons following administration of the Parkinsonian toxin MPTP. Journal of Neurochemistry, 74, 721729
[121] Wagenfeld, A., Yeung, C.H., Shivaji, S., Sundareswaran, V.R., Ariga, H., Cooper, T.G. (2000) Expression and cellular localization of contraception-associated protein. J. Androl., 21, 954-963.

[122] West, A.B., Lockhart, P.J., O'Farell, C., Farrer, M.J. (2003) Identification of a novel gene linked to parkin via a bi-directional promoter. J. Mol. Biol., 326, 11-19.

[123] Wilkinson, K.D. (1997) Regulation of ubiquitin-dependent processes by deubiquitinating enzymes. FASEB J., 11, 1245-1256.

[124] Xu, P.Y., Liang, R., Jankovic, J., Hunter, C., Zeng, Y.X., Ashizawa, T., Lai, D., Le, W.D. (2002) Association of homozygous 7048 G7049 variant in the intron six of Nurr1 gene with Parkinson's disease. Neurology, 58, 881-884.

[125] Yang, Y., Nishimura, I., Imai, Y., Takahashi, R., Lu, B. (2003) Parkin suppresses dopaminergic neuron-selective neurotoxicity induced by Pael-R in Drosophila. Neuron, 37, 911-924.

[126] Yu, W., Centonze, V.E., Ahmad, F.J., Baas, P.W. (1993) Microtubule nucleation and release from the neuronal centrosome. $J$ Cell Biol., 122, 349-359.

[127] Zetterstrom, R.H., Solomin, L., Jansson, L., Hoffer, B.J., Olson, L., Perlmann, T. (1997) Dopamine neuron agenesis in Nurr1-deficient mice. Science, 276, 248-250.

[128] Zhang, Y., Gao, J., Chung, K.K., Huang, H., Dawson, V.L., Dawson, T.M. (2000) Parkin functions as an E2-dependent ubiquitin- protein ligase and promotes the degradation of the synaptic vesicle-associated protein, CDCrel-1. Proc. Natl. Acad. Sci. USA, 97, 13354-13359.

[129] Zhao, J., Ren, Y., Jiang, Q., Feng, J. (2003) Parkin is Recruited to the Centrosome in Response to Inhibition of Proteasomes. J. Cell Sci., 116, 4011-4019.

[130] Zhou, Q.Y., Palmiter, R.D. (1995) Dopamine-deficient mice are severely hypoactive, adipsic, and aphagic. Cell, 83, 1197-1209.

[131] Zimprich, A., Asmus, F., Leitner, P., Castro, M., Bereznai, B., Homann, N., Ott, E., Rutgers, A.W., Wieditz, G., Trenkwalder, C., Gasser, T. (2003) Point mutations in exon 1 of the NR4A2 gene are not a major cause of familial Parkinson's disease. Neurogenetics., Jun 25 (Epub ahead of print, DOI 10.1007/s10048-003-0156-x). 